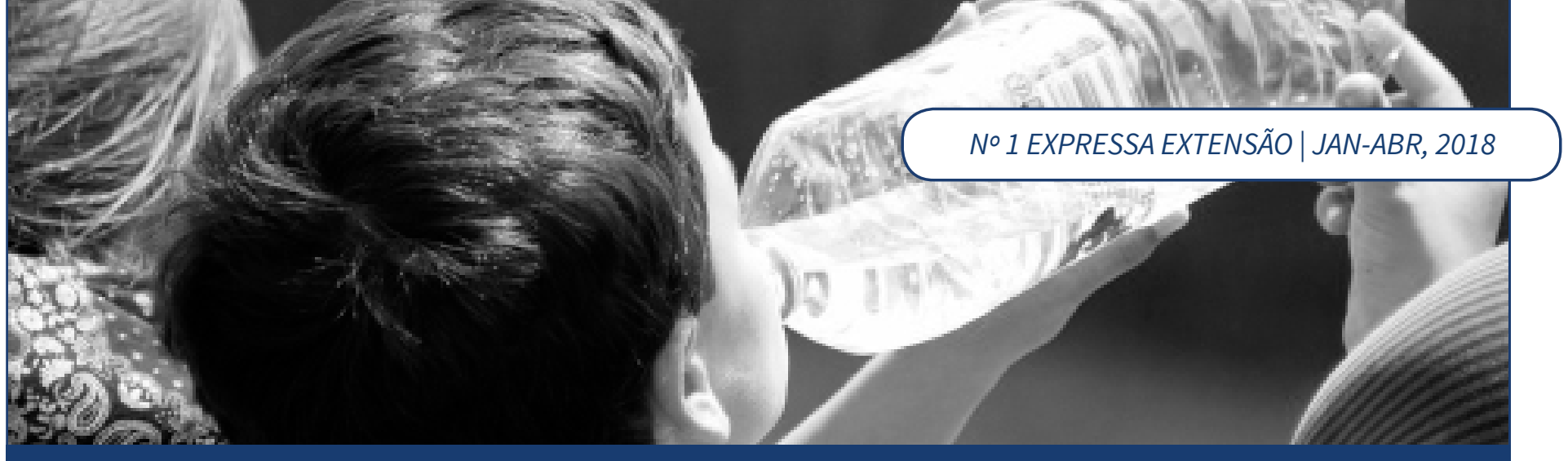

\title{
A ÁGUA E A SAÚDE NO MEIO RURAL: EDUCAÇÃO AMBIENTAL NAS ESCOLAS
}

WATER AND HEALTH IN THE RURAL ENVIRONMENT: ENVIRONMENTAL EDUCATION IN SCHOOLS

Mirele Bragato ${ }^{1}$ Bárbara Ponzilacqua Silva² Cristina Mendes Peter ${ }^{3}$ Tony Picoli ${ }^{4}$ João Luíz Zani ${ }^{5}$

\section{RESUMO}

É por meio da educação que se formam cidadãos conscientes de seu papel na sociedade. A educação ambiental deve estar presente em todas as séries escolares, em diferentes níveis de profundidade. Este processo educativo é fundamental, mostrando aos estudantes correlações entre sociedade, cultura e ecologia, contribuindo assim, para o fortalecimento da sua responsabilidade na conservação do meio ambiente. O objetivo foi discutir com escolares da zona rural sobre a nossa responsabilidade perante a conservação do meio ambiente e principalmente a conservação da água. As atividades foram conduzidas com crianças de escolasda zona rural da região sul. O trabalho foi desenvolvido através de visitas as escolas e visitas a locais relacionados às diferente temáticas abordadas. Foram visitados fontes preservadas, represas, o Arroio Pelotas, a Lagoa dos Patos, e a praia do Cassino, discutindo a conservação dos recursos hídricos e contaminação por resíduos. Tudo foi registrado através de fotografias e redações elaboradas pelas crianças. Em cada escola foram expostas as fotografias e redações em um grande painel, realizado palestras e discutido junto com os familiares. Com isso pode-se oportunizar uma visão diferenciada da realidade ambiental da região e uma conscientização através de mudança de atitude nas escolas, nas suas propriedades e comunidades rurais.

Palavra-chave: Educação ambiental. Água. Escolas.

\footnotetext{
${ }^{1}$ Aluna de Graduação. Faculdade de Veterinária, Universidade Federal de Pelotas. E-mail: mirelli_bragatto@hotmail.com. ${ }^{2}$ Formada em Medicina Veterinária na Universidade Federal de Pelotas. Aluna de Pós-graduação em Zootecnia e Engenharia de Alimentos, FZEA, Universidade de São Paulo, Pirassununga, SP. E-mail: bponzilacqua@hotmail.com. ${ }^{3}$ Aluno de Pós-graduação em Veterinária. Faculdade de Veterinária, Universidade Federal de Pelotas. E-mail: cristina_peter@hotmail.com. ${ }^{4}$ Pós-doutorando em Veterinária. Faculdade de Veterinária, Universidade Federal de Pelotas. E-mail: tony_picoli@yahoo.com.br. ${ }^{5}$ Professor Associado. Faculdade de Veterinária, Universidade Federal de Pelotas. E-mail: jluizzani@outlook.com.br.
} 


\begin{abstract}
It is through education that citizens are formed aware of their role in society. Environmental education must be present in all school grades at different levels of depth. This educational processes fundamental, showing students correlations between society, culture and ecology, this contributing to the strengthening of its responsibility in the conservation of the environment. The objective was to discuss with rural students about our responsibility to the conservation of the environment and especially the conservation of water. The activities were conducted with children from rural schools in the southern region. The work was developed through visits to schools and visits to sites related to the different topics addressed. Preserved fountains, dams, Arroio Pelotas, Lagoa dos Patos, and the beach of the Casino were discussed, discussing the conservation of water resources and contamination by waste. Everything was recorded through photographs and essays written by children. At each school were exposed the photographs and essays on a large panel, held lectures and discussed with family members. This can provide a differentiated view of the region's environmental reality and an awareness of changes in attitude in schools, rural properties and communities.
\end{abstract}

Keywords: Environmental education. Water. Schools.

\title{
INTRODUÇÃO
}

Entendem-se como educação ambiental os processos pelo qual o indivíduo e a coletividade constroem valores sociais, conhecimentos, habilidades, atitudes e competência voltadas para conservação do meio ambiente. Esta ação deve ter uma grande dimensão tanto na sociedade como no universo educativo, potencializando o engajamento dos diversos sistemas de conhecimento, capacitação de profissionais e da comunidade universitária numa pesquisa interdisciplinar (LIMA et al., 2016).

Neste contexto é importante ressaltar a importância do professor como instrumento de transição, que contribui para a formação de cidadãos capazes de desenvolver visões críticas e de transformar o meio ambiente que estão inseridos. Dada à importância do professor, entende-se que o mesmo deve buscar meios para propagar o conhecimento de forma clara e coerente, identificando assim 
técnicas apropriadas para o ensino (MORAES et al. 2015).

De acordo com Abílio et al. (2011), ao introduzir a questão ambiental no cotidiano das pessoas, busca-se uma nova perspectiva de relação entre ser humano, sociedade, natureza e também promover uma reavaliação de valores e atitudes na convivência entre os seres humanos, podendo assim atuar em conjunto para que se possa procurar soluções para problemas ambientais. Portanto é fundamental o estabelecimento de políticas públicas que fortaleçam as instituições de ensino, principalmente as escolas de educação básica devido à importância destas na formação social, cultural e ética dos cidadãos.

Em Victoria na Austrália, o governo mantém um programa de educação ambiental nas escolas com ações que vão desde o controle de consumo de água nas escolas, do gerenciamento sustentável da água até o monitoramento da saúde dos rios pelas comunidades locais. Este programa apoia voluntários que plantam árvores nas margens dos rios, riachos e nascentes. Cuidam das águas subterrâneas e estuários, monitorando e denunciando irregularidades. Também mantém uma biblioteca virtual com publicações de pesquisas para professores e estudantes sobre as águas na sua região. Isto ajuda muito na conservação das águas e na educação ambiental (VICTORIA GOVERNMENT STATE, 2017).

É importante destacar que vivemos em um mundo contemporâneo, em épocas de grandes transformações sociais, políticas, econômicas e ambientais. Diante deste fato surge a necessidade da disseminação de novos valores de preservação do meio ambiente e sustentabilidade que privilegie a natureza e a comunidade, primando assim por uma melhor qualidade de vida para as gerações futuras (SOUZA et. al., 2011).

No país a educação ambiental é definida como: "Art.1: Entende-se por educação ambiental os processos por meio dos quais o indivíduo e a coletividade constroem valores sociais, conhecimentos, habilidades, atitudes e competências voltadas para a conservação do meio ambiente, bem de uso comum do povo, essencial à sadia qualidade de vida e sua sustentabilidade" (LEI N 9.795, de 27 de abril de 1999).

A educação produz mudança de comportamento e atitudes em relação à problemática ambiental. É por meio da educação que se farão cidadãos conscientes do seu papel dentro de uma sociedade ambientalmente justa. A educa- 
ção ambiental deve estar presente em todas as séries escolares, sendo importante na formação de cidadãos críticos perante a sociedade, num processo contínuo de aprendizagem de uma filosofia participativa que envolve tanto a família, a escola e a sociedade (COSTA; SCHWANKE, 2010). Sua introdução nas escolas deve apresentar-se em diferentes níveis de profundidade, desde os primeiros anos escolares. Este processo educativo é de fundamental importância, demostrando assim aos estudantes, as diferentes correlações entre sociedade, cultura e ecologia, fortalecendoassim o respeito pela natureza e a sua responsabilidade perante a conservação do meio ambiente. Conforme Silva e Leite (2008), não haverá sustentabilidade, sem educação ambiental. Para isso são necessáriasmudanças nos modelos educacionais da sociedade. Afirmam que um dos maiores desafios é fazer com que aeducação ambiental seja um processo de construção e reconstrução de conhecimento que possibilite interações com os conteúdos trabalhados nas escolas, permitindo mudanças de percepção, pensamentos e de atitudes.

Segundo Jesus e Martins (2002), o conteúdo da educação ambiental deve ter origem no levantamento da problemática ambiental que é vivenciada rotineiramente pelos alunos, havendo assim a possibilidade de correlacionar ciências, as questões imediatas e as questões mais amplas a respeito de meio ambiente, já que a educação ambiental nas escolas não é ofertada como uma disciplina e sim enquadrada em disciplinas básicas escolares ou simplesmente não se faz presente. Há a necessidade da introdução de estudos dentro das escolas sobre a temática do meio ambiente correlacionando com o cotidiano dos estudantes, despertando assim o interesse a respeito da preservação da biodiversidade e desenvolvimento sustentável, já que a degradação ambiental atualmente é considerada uma das maiores preocupações dos órgãos públicos e da sociedade. Faz-se necessário a elaboração de ações de caráter educativo, para o desenvolvimento sustentável, assegurando assim, a preservação dos recursos naturais para as futuras gerações.

Bacci e Pataca (2008) abordam a educação para água nas escolas em duas dimensões, a espacial e a temporal, acreditando que sem este tipo de abordagem não é possível enfrentar a fragmentação do conhecimento nos currículos escolares. Justificam que é necessário a compreensão da relação homem-natureza ao longo do tempo e que assim é possível uma análise integrada de problemas reais, facilitando a relação de conceitos, procedimentos e atitudes.

O presente trabalho tem por finalidade, descrever as atividades desenvol- 
vidas acerca de conscientização ambiental e sociocultural com estudantes da zona rural do Município de Pelotas / Rio Grande do Sul, através de visitas e palestras em locais de preservação ambiental, bem como estações de tratamento de água e de reciclagem de lixo. O objetivo deste projeto foi trabalhar discutindo com escolares sobre a nossa responsabilidade perante a conservação do meioambiente e principalmente a conservação da água.

\section{AÇÕES EXTENSIONISTAS}

O trabalho foi desenvolvido com estudantes de escolas públicas da zona rural da regiãosul do Rio Grande do Sul envolvendo aproximadamente 100 crianças de 8 a 13 anos de idade, além de professores e familiares ligados a estes alunos. O fluxograma a seguir demonstra a sequência das etapas metodológicas utilizadas para o desenvolvimento do trabalho.

\begin{tabular}{|c|c|c|c|c|}
\hline $\begin{array}{c}\text { Escolha } \\
\text { do local da } \\
\text { atividade } \\
\text { extensionista }\end{array}$ & $\begin{array}{c}\text { Escolha das } \\
\text { turmas em } \\
\text { cada escola }\end{array}$ & $\begin{array}{c}\text { Visita do } \\
\text { público } \\
\text { alvoaos locais } \\
\text { escolhidos }\end{array}$ & $\begin{array}{c}\text { Atividade } \\
\text { de discussão } \\
\text { em sala de } \\
\text { aula sobre a } \\
\text { atividade }\end{array}$ & $\begin{array}{c}\text { Palestras, exposição } \\
\text { fotográfica e de } \\
\text { redaçõescom a } \\
\text { participação dos pais e } \\
\text { comunidade local }\end{array}$ \\
\hline
\end{tabular}

Através de diferentes atividades realizadas na escola e fora dela, discutiu-se com a comunidade escolar o problema do lixo e da poluição da água, assim como a necessidade da sua conservação para as futuras gerações. As crianças e os professores tiveram a oportunidade de conhecer locais onde a natureza ainda é preservada e locais que contribuem para o menor impacto ambiental ocasionado pelas atitudes do homem. Assim foram visitados diferentes locais na zona urbana e na rural para conhecimento e discussão. Foram visitadas propriedades rurais onde se praticava conservação de fontes usando o reflorestamento com espécies nativas. Também foram visitadas represas onde é feita captação de água e observado todo o tratamento da água nas estações de tratamento para consumo humano na zona rural e urbana. 
Algumas escolas se localizam próximo ao Arroio Pelotas, que foi visitado pelos escolares, onde foi observado e discutido a necessidade de conservação da mata ciliar, o assoreamento e poluição do rio principalmente por objetos plásticos como garrafas e sacolas que ficam às margens em grande quantidade. Durante a visita foram feitas limpezas das margens com coleta deste material pelos escolares. Também foi discutido o problema de resíduo de agrotóxico que alcançam o rio já que existem muitas lavourasàs margens do rio.

Outro local visitado foi a Lagoa dos Patos, um ecossistema importantíssimo para a região e que possui muitas peculiaridades. Os escolares conseguiram estabelecer uma relação estre a conservação do Arroio Pelotas e a Lagoa dos Patos já que a poluição do rio alcança a lagoa causando danos principalmente à pesca. Foram visitados os barcos e ouvidos relatos de pescadores sobre as mudanças que ocorreram nos últimos anos na lagoa e na pesca. A necessidade da conservação da maior laguna de água doce do planeta que recebe água salgada e que modifica a sua fauna ao longo do ano. A sua importância para a alimentação das populações da região no presente e no futuro. Também foi visitado a reserva de mata nativa municipal que fica as margens da lagoa.

Na praia do Cassino foi possível discutir a importância do mar para a vida no planeta, a produção de oxigênio pelo plâncton, as marés, as dunas e fauna local. Muitos escolares nunca tinham visitado uma praia de água salgada.

Em visita à Cooperativa de Catadores de Lixo Reciclável de Pelotas, as crianças tiveram a oportunidade de visualizar a quantidade de lixo reciclável gerada e que sem o trabalho daquelas pessoas, aquele lixo iria contribuir para a poluição ambiental. Nas escolas, foram realizadas palestras de conscientização para as crianças, utilizando recursos como vídeos, teatro e música, para que o ensino não se torne maçante para o público infantil. As crianças puderam discutir a importância da conservação dos recursos hídricos e da redução de resíduos.

Todas as visitas feitas eram registradas através de fotografias pelos alunos assim como redações foram elaboradas pelos próprios estudantes em sala de aula após as saídas. Algum tempo depois, aos sábados, foram expostas em cada escola as fotografias e redações dos estudantes em grandes e coloridos painéis e ainda foramrealizadas novas palestras, apresentados vídeos, com novas formações de grupos entre os estudantes para discussão. Nestas atividades os familiares foram convidados a participar, com grande engajamento. 


\section{RESULTADOS E DISCUSSÃO}

Foi possível realizar atividades com as crianças na zona rural, onde as mesmas tiveram oportunidade de conhecer lugares, debater temas e realizar tarefas ligadas à preservação do meio ambiente, melhorando seu entendimento sobre a importância do ecossistema e o meio ambiente onde vivem.

As dinâmicas empregadas visaram aumentar o conhecimento sobre água e a importância da sua conservação. Para isto foram realizadas, palestras, visitas e exposição de fotografias de lugares ligados a este tema, onde a comunidade escolar e família foram incluídos. Esta metodologia de trabalho tem como princípio que o aprendizado sobre a questão ambiental deve partir da realidade concreta, dos problemas ambientais vividos nos locais onde as escolas estão inseridas, permitindo uma discussão mais palpável e, portanto um aprendizado mais sólido (JESUS; MARTINS, 2002).

O resultado foi uma maior conscientização de todos os envolvidos nas atividades extensionistas, principalmente das crianças que são a base parao futuro. Uma maior consciência do quão importante é a preservação do ambienteonde elas vivem e sua conservação foi observada através das discussões e exposições realizadas por elas.

Nas escolas onde foi desenvolvido o trabalho os estudantes são na sua maioria de origem, alemã e italiana ede afrodescendentes. Pode-se constatar a grande motivação e interesse por parte dos alunos, em buscar conhecimento sobre formas de preservar os recursos hídricos. Através de métodos simples como, confecção de filtros de purificação de água por decantação e o consumo consciente da água.

Nos encontros posteriores às visitas, pôde-se avaliar o conhecimento obtido pelas crianças através das atividades realizadas. Muitas delas mudaram a postura adotada após os dias de passeio, e acabaram por passar conhecimentos para as crianças que não tiveram a oportunidade de sair, para familiares e amigos. 0 consumo consciente de água, e sua preservação passaram a ser atividade diária dos alunos não apenas na escola, mas também em suas casas. $O$ envolvimento de familiares e da comunidade do entorno das escolas é muito importante para o processo de ensino e aprendizagem, também para tomada de atitudes concretas no sentido de melhorar os recursos hídricos da região onde a escola está inserida, 
por isso as atividades após as visitas. Este envolvimento de familiares e comunidade é importantíssimo no processo de educação ambiental (COSTA; SCHWANKE, 2010). Assim as crianças puderam aprender ainda mais sobre o mundo em que vivem e sobre os cuidados que se deve ter para a manutenção do planeta para o futuro.

\section{CONCLUSÕES}

As atividades de extensão têm um grande valor, pois a partir destas, as comunidades podem abordar temas que estão em seu cotidiano. As atividades estimularam os estudantes da zona rural a discutir sobre a temática ambiental, entender como podem intervir em suas escolas e famílias para que se preserve cada vez mais o meio ambiente.

A introdução da educação ambiental nas escolas rurais através de palestras, visitas a locais relacionados e formação de grupos entre os estudantes é um método eficiente para compreender um pouco mais sobre problemática ambiental atual.

\section{REFERÊNCIAS}

ABÍLIO, F.J.P.; DA SILVA, F.H.; DE MELO R. T. L. Educação ambiental no Bioma Caatinga: formação continuada de professores de escolas públicas de São João do Cariri, Paraíba. Pesquisa em Educação Ambiental, v. 5, n. 1, p. 171-193, 2011.

BACCI, D. L.C.; PATACA, E.M. Educação para água. Revista Estudos Avançados, v. 22, n. 66, p. 211-226, 2008.

BRASIL. Dispõe sobre a educação ambiental, Institui a Política Nacional de Educação Ambiental e dá outras providências. Lei n ${ }^{\circ}$ 9795. Diário Oficial [da] República Federativa do Brasil, Brasília, DF, Casa Civil, 28 abr. 1999.

BRASIL. Conceitos e práticas em educação ambiental nas escolas, vamos cuidar do Brasil. 2007.Disponível em: <http://portal.mec.gov.br/dmdocuments/publicacao3.pdf>.Acesso em: 15 ago. 2017. 
COSTA,Raquel.; SCHAMKE, Cibele.Atitudes relacionadas ao meio ambiente: uma responsabilidade da educação ambiental.Educação Ambiental em Ação, v. 34, n. 9, dez. 2010/ fev. 2011.Disponível em: <http://www.revistaea.org/artigo.php?idartigo=942>. Acesso em: 10 ago. 2017.

JACOBI, P. et al. Educação ambiental, cidadania e sustentabilidade. Cadernos de pesquisa, v. 118, n. 3, p.189-205, 2003.

JESUS, E. L.; MARTINS, A. L. U. Educação ambiental: impasses e desafiosnaescolapública. In:PEDRINI, A. G. (Org.). 0 contrato social da ciência:unindosaberesna educação ambiental. Petrópolis: Vozes, 2002. p.172-184.

LIMA, G.M.M.; SOBRINHO, W.A.M.C.; DE SOUZA JUNIOR, J.I. Educação ambiental e implantação de horta escolar. Cadernos de Agroecologia, v. 10, n. 3, 2016.

MORAES, K. F.; DA CRUZ, M. R. O ensino da educação ambiental. Revista Direito e Política, v. 10, n. 2, p. 928-945, 2015.

RUY, R. A. V.A educação ambiental na escola. Revista Eletrônica de Ciências, 2004. Disponível em: <www.cdcc.usp.br/ciencias/artigos>. Acesso em: 12 ago. 2017.

SILVA, M.M.P., LEITE, V.D. Estratégias para a realização de educação ambiental nas escolas de ensino fundamental. Revista Eletrônica do Mestrado em Educação Ambiental, v.20, n. 1, p.327-392, 2008.

SOUZA, J.C.M.; GONÇALVES, L.; SOARES, A.M.D. A educação ambiental na recuperação e conservação de recursos naturais: a percepção de assentados rurais no cerrado goiano = Environmental education in recovery and conservation of natural resources: the perception of rural settlements in cerrado goiano. Campo-território: revista de geografia agrária, v. 6, n. 11, p. 312-337, 2011.

VICTORIA GOVERNMENT STATE. 2017. Environment, land, water and planning. Disponível em: <https://www.water.vic.gov.au/liveable-cities-and-towns/water-education>. Acesso em: 15 dez. 2017.

Data de recebimento: 30 de outubro de 2017.

Data de aceite para publicação: 11 de janeiro de 2018. 